\title{
Incidence of dental caries in primary dentition and risk factors: a longitudinal study
}

\section{Patrícia CORRÊA-FARIA Suzane PAIXÃO-GONÇALVES Saul Martins PAIVA Isabela Almeida PORDEUS}

Universidade Federal de Minas Gerais - UFMG, School of Dentistry, Department of Pediatric Dentistry and Orthodontics, Belo Horizonte, MG, Brazil.

Declaration of Interests: The authors certify that they have no commercial or associative interest that represents a conflict of interest in connection with the manuscript.

\section{Corresponding Author:}

Patrícia Corrêa-Faria

E-mail: patriciafaria.faria09@gmail.com

DOI: 10.1590/1807-3107BOR-2016.vol30.0059

Submitted: Jul 03, 2015

Accepted for publication: Jan 20, 2016

Last revision: Mar 22, 2016

\begin{abstract}
The objectives of this prospective, longitudinal, population-based study were to estimate the incidence of dental caries in the primary dentition, identify risk factors and determine the proportion of children receiving dental treatment, through a two-year follow up. The first dental exam was conducted with 381 children aged one to five years, at health centers during immunization campaigns; 184 of them had dental caries and 197 had no caries experience. The second exam was carried out two years later at a nursery or at home with the same individuals who participated in the first exam. The diagnosis of dental caries was performed using the $\mathrm{dmft}$ criteria. Parents were interviewed regarding socioeconomic indicators. Descriptive, bivariate and adjusted Poisson regression analyses were performed. Among the 381 children, 234 were reexamined after two years (non-exposed: 139; exposed: 95). The overall incidence of dental caries was $46.6 \%$. The greatest incidence of dental caries was found in the group of children with previous caries experience (61.1\%). Among the children without dental caries in the first exam, $36.7 \%$ exhibited caries in the second exam. The majority of children $(72.6 \%)$ received no treatment for carious lesions in the two-year interval between examinations. Children with previous dental caries (RR: 1.52, 95\%CI: 1.12-2.05) had a greater risk of developing new lesions, compared with the children without previous dental caries. The incidence of dental caries was high and most of children's caries were untreated. Previous caries experience is a risk factor for developing new carious lesions in children.
\end{abstract}

Keywords: Dental Caries; Tooth, Deciduous; Oral Hygiene; Incidence.

\section{Introduction}

Dental caries is one of the most frequent chronic conditions in childhood. Approximately $50 \%$ of preschool children in different countries have caries experience. ${ }^{1}$ This estimate is confirmed in studies conducted in Brazil, where prevalence rates range from $20.3 \%{ }^{2}$ to $53.6 \%{ }^{3}$ Dental caries exerts a negative impact on the quality of life of both the child and the family, ${ }^{2}$ and is considered a public health problem.

The etiology of dental caries in childhood is associated with eating habits ${ }^{4,5}$ irregular tooth brushing ${ }^{6,7}$ and socioeconomic indicators. ${ }^{8}$ Children from economically vulnerable families have a higher 
prevalence rate of dental caries.,10 The same is true for children whose mothers have a low level of education. ${ }^{11}$ The socioeconomic status of the family can influence parents'/caregivers' perceptions regarding the oral health of their children. Parents with a disadvantaged socioeconomic status may have less knowledge regarding the factors associated with caries and dental care needs, as well as less access to healthcare services..$^{5,12,13}$

Approximately $48 \%$ of Brazilian children aged five years have untreated dental caries, ${ }^{13}$ which can cause pain and affect both their nutritional status and physical development. ${ }^{14}$ Untreated dental caries is also the most common reason for hospital admissions. ${ }^{15}$ Considering the significant proportion of untreated caries and its impact on quality of life, it is important to identify children with dental caries and determine the risk factors of this adverse oral health condition. The assessment of caries-related risk factors is useful to the planning of public health policies based on scientific evidence, and is crucial to identifying the early stages of the disease in children who are susceptible to aggravation of tooth decay. ${ }^{16}$

The determination of factors that may favor the occurrence of dental caries is accomplished primarily through cross-sectional studies. However, the cross-sectional design does not allow the determination of causality among variables, and provides weaker evidence of associations. Thus, longitudinal studies are needed, because they allow cause-and-effect relationships to be determined, and risk factors to be confirmed. ${ }^{17}$ Longitudinal studies also provide data on the incidence of adverse health conditions. However, information on the incidence of caries in the primary dentition remains scant. ${ }^{18,19}$ Incidence data are important to assessing the magnitude of the health problem and the effectiveness of preventive measures, as well as to enabling access to health services.

The aim of the present study was to assess the oral health status of Brazilian children in a two-year period, and to identify the incidence of carious lesions, risk factors and the frequency of deciduous teeth that remain untreated.

\section{Methodology}

A longitudinal study was conducted in the city of Diamantina, located in the northern portion of the state of Minas Gerais, in southeastern Brazil. The Human Development Index for the city is $0.716 .^{20}$ According to the last census of the Instituto Brasileiro de Geografia e Estatística - IBGE, ${ }^{21}$ Diamantina has a population of 45,880 inhabitants, 2992 of whom are children aged two to six years. The study population included children from four to seven years of age.

\section{Study design}

This study was conducted at two moments: baseline (T0) and follow-up (T1). In 2010 and 2011 (T0), 381 children aged one to five years were examined to determine prevalence of dental caries and identify associated factors, and their parents were interviewed regarding socioeconomic indicators. At a second moment (2012 and 2013) (T1) the children were reexamined to verify dental caries incidence and identify risk factors; in addition, it was ascertained whether the children diagnosed with caries in the first exam received dental treatment.

\section{T0 - baseline}

In the first phase, the study population included children from one to five years of age, who had been treated at the basic healthcare units $(n=10)$ of the city during immunization campaigns held in 2010 and 2011. In these immunization campaigns, vaccination coverage was higher than $90 \%$. In 2010, 3713 children were immunized (coverage: 97.28\%), whereas in 2011, 3107 (coverage: 99.29\%) children were treated during immunization campaigns. The sample size for T0 was calculated considering a $44.8 \%$ prevalence rate for caries in the deciduous dentition, ${ }^{22}$ a $95 \%$ confidence interval and a 5\% standard error, which established a minimum sample of 380 children. Systematic sampling was adopted for the purpose of randomization, using the following procedure: the children were arranged in a line; the first child was examined, the second was not, the third was examined, and so on.

Prior to the fieldwork, ten examiners underwent a training and calibration exercise for the diagnosis of dental caries. Calibration was performed using 
images of different clinical situations on two separate occasions, with a one-week interval between sessions. The minimum kappa intraexaminer agreement was 0.81 , and the maximum was 0.90 . The minimum kappa interexaminer agreement was 0.80 , and the maximum was 1 .

During the exam, the child remained seated in front of the examiner and facing a window to make utmost use of natural light. Dental caries was diagnosed using the criteria of the World Health Organization. ${ }^{23}$ Dental caries was dichotomized as absent or present. Oral hygiene quality was evaluated based on the presence of biofilm. Tooth surfaces were scraped with a clinical probe, and the presence of biofilm indicated unsatisfactory oral hygiene.

The parents/caregivers were interviewed to determine socioeconomic indicators (mother's schooling, monthly household income and place of residence) and child's age and sex. After the diagnosis of dental caries, all parents/caregivers and children received instructions regarding oral hygiene and diet. Parents/caregivers of children who had carious lesions were informed of the need for treatment, and were instructed to seek dental services at the university clinic or family health units of the Brazilian public healthcare system.

\section{T1 - follow-up}

This second phase was conducted by two researchers, who contacted the parents/caregivers and children to invite them to participate in the reevaluation of oral conditions. A clinical examination was carried out at the place where the child spent most of the time: nursery school or home. In the event that the child and parents/caregivers were not found during telephone contact or upon the first visit, three attempts were made before considering the data as lost.

The children were divided in two groups based on the presence of dental caries in first exam. The exposed group was composed of children with previous dental caries experience $(n=184)$, and the non-exposed group ( $\mathrm{n}=197)$, of children who had no previous dental caries experience. The diagnosis of new cases of dental caries and oral hygiene was performed using the same criteria employed during the first exam. The incidence of dental caries was determined by comparing the two oral examinations. During the second exam, the researchers were blinded to each of the groups. During the second interview, parents/caregivers confirmed the information on socioeconomic indicators.

The treatment of carious lesions during the two-year interval was determined by comparing the two exams. Each carious tooth observed during the first examination, either remained with caries or had received some form of treatment (restoration or extraction). For cases in which a tooth was missing, the parents/caregivers were asked to explain why it was missing, and there was also the possibility of exfoliation, considering the child's age and the presence/absence of the contralateral tooth.

\section{Statistical analysis}

The data were analyzed using the Statistical Package for the Social Sciences (SPSS for Windows version 20.0, SPSS Inc., Chicago, USA). Associations were tested using bivariate analysis (chi-squared test and McNemar's test) between the outcome variable (new dental caries) and the independent variables (socio-demographic and clinical characteristics). Poisson regression with robust variance was used to determine interactions among the variables. The magnitude of the association of each factor with further episodes of dental caries was assessed using non-adjusted and adjusted relative risk (RR), respective 95\% confidence intervals (CI) and p-values (Wald test). Explanatory variables with a $p$-value of $\leq 0.25$ in the bivariate analysis were incorporated into the multivariate model.

This study received the approval of the Human Research Ethics Committee of the Universidade Federal de Minas Gerais - UFMG (Brazil) (protocol: 181/2010). The participants' rights were protected and parents/caregivers read and signed a statement of informed consent prior the participation of their children.

\section{Results}

\section{T0 - baseline}

Table 1 shows the characteristics of participants. The prevalence of dental caries was $48.3 \%$. The 
statistical analysis (chi-squared test and Poisson regression with robust variance) revealed that dental caries was significantly associated with inadequate oral hygiene $(p<0.001)$, low income $(p<0.001)$ and lower level of mother's schooling $(p=0.001)$. In the adjusted multivariate regression model, inadequate oral hygiene (PR: 3.14; 95\%CI: 1.13-2.15) and low income (PR: 1.56; 95\%CI: 2.33-4.24) remained associated with a greater prevalence rate of dental caries, independently of

Table 1. Characteristics of participants at baseline $(n=381)$.

\begin{tabular}{lc}
\hline Characteristics & $\mathrm{n}(\%)$ \\
\hline Sex & $188(49.3)$ \\
Male & $193(50.7)$ \\
Female & \\
Dental caries & $197(51.7)$ \\
No & $184(48.3)$ \\
Yes & \\
Place of residence & $276(72.4)$ \\
Urban area & $105(27.6)$ \\
Rural area & \\
Mother's schooling & $146(39.5)$ \\
$>8$ years & $224(60.5)$ \\
$\leq 8$ years & \\
Household income & $87(22.9)$ \\
$>2$ times monthly min wage & $293(77.1)$ \\
$\leq 2$ times monthly min wage & \\
Age & \\
Minimum: 1 year & - \\
Maximum: 5 years & - \\
Median: 3 years & \\
\hline
\end{tabular}

the other variables (place of residence, mother's schooling, child's age and sex).

\section{T1 - follow-up}

Among the 381 children, 234 were reexamined after two years, corresponding to a $61.4 \%$ response rate (exposed group: 51.63\%; non-exposed group: $70.55 \%)$. The main reasons for the losses were moving to another city or address and absence from daycare or from place of residence after three attempts to visit.

Among the children examined, 55.1\% were male and the mean age was $5.33( \pm 1.08)$ years. Most mothers had schooling $\leq$ eight years (52.6\%), and $84.2 \%$ of the families had a household income $\leq$ twice that of the Brazilian monthly minimum wage.

Among the 139 children who had no dental caries experience at baseline, 51 (36.7\%) developed carious lesions during the two-year follow up. Among the 95 children with dental caries experience at the first exam, 58 (61.1\%) developed new carious lesions during the follow-up. Thus, a total of 109 $(51+58)(46.6 \%)$ children had carious lesions in the follow-up time. Most caries remained untreated at the end of the follow-up period (Tables 2 and 3). Comparing the two dental examinations, a high percentage of children (72.6\%) diagnosed with carious lesions at the first exam remained without treatment at the second exam. The remaining children had been submitted to restoration or extraction of at least one decayed tooth.

In the bivariate analysis, new caries lesions were significantly associated with inadequate oral hygiene $(p=0.009)($ Table 4$)$. The risk factors of these new

Table 2. Characteristics of carious lesions after two years (upper teeth).

\begin{tabular}{lcccccccccc}
\hline $\begin{array}{l}\text { Dental caries } \\
\text { (Second exam) }\end{array}$ & \multicolumn{7}{c}{ Caries diagnosed at first examination } \\
\cline { 2 - 10 } & Tooth 55 & Tooth 54 & Tooth 53 & Tooth 52 & Tooth 51 & Tooth 61 & Tooth 62 & Tooth 63 & Tooth 64 & Tooth 65 \\
\hline Decayed (\%) & $22(88.0)$ & $22(91.6)$ & $3(50.0)$ & $26(81.2)$ & $22(50.0)$ & $20(45.4)$ & $16(59.2)$ & $4(66.6)$ & $23(71.9)$ & $11(57.9)$ \\
Restored without caries (\%) & $3(12.0)$ & $1(4.2)$ & $3(50.0)$ & $6(18.8)$ & $8(18.1)$ & $8(18.2)$ & $9(33.3)$ & $2(33.4)$ & $5(15.7)$ & $7(36.9)$ \\
Restored with decay (\%) & $0(0.0)$ & $1(4.2)$ & $0(0.0)$ & $0(0.0)$ & $2(4.5)$ & $1(2.3)$ & $0(0.0)$ & $0(0.0)$ & $2(6.2)$ & $1(5.2)$ \\
Missing due to caries (\%) & $0(0.0)$ & $0(0.0)$ & $0(0.0)$ & $0(0.0)$ & $5(11.4)$ & $5(11.3)$ & $2(7.5)$ & $0(0.0)$ & $2(6.2)$ & $0(0.0)$ \\
Exfoliated (\%) & $0(0.0)$ & $0(0.0)$ & $0(0.0)$ & $0(0.0)$ & $7(16.0)$ & $10(22.8)$ & $0(0.0)$ & $0(0.0)$ & $0(0.0)$ & $0(0.0)$ \\
Total (\%) & $25(100)$ & $24(100)$ & $6(100)$ & $32(100)$ & $44(100)$ & $44(100)$ & $27(100)$ & $6(100)$ & $32(100)$ & $19(100)$ \\
\hline
\end{tabular}


Table 3. Characteristics of carious lesions after two years (lower teeth).

\begin{tabular}{lcccccccccc}
\hline \multirow{2}{*}{$\begin{array}{l}\text { Dental caries } \\
\text { (Second exam) }\end{array}$} & \multicolumn{10}{c}{ Caries diagnosed at first examination } \\
\cline { 2 - 10 } & Tooth 75 & Tooth 74 & Tooth 73 & Tooth 72 & Tooth 71 & Tooth 81 & Tooth 82 & Tooth 83 & Tooth 84 & Tooth 85 \\
\hline Decayed (\%) & $19(47.5)$ & $28(65.1)$ & $4(100)$ & $4(100)$ & $4(50.0)$ & $5(55.5)$ & $6(85.7)$ & $6(85.7)$ & $31(72.1)$ & $21(47.8)$ \\
Restored without caries (\%) & $15(37.5)$ & $14(32.5)$ & $0(0.0)$ & $0(0.0)$ & $1(12.5)$ & $1(11.1)$ & $0(0.0)$ & $1(14.3)$ & $9(20.9)$ & $19(43.2)$ \\
Restored with decay (\%) & $5(12.5)$ & $0(0.0)$ & $0(0.0)$ & $0(0.0)$ & $0(0.0)$ & $0(0.0)$ & $0(0.0)$ & $0(0.0)$ & $0(0.0)$ & $2(4.5)$ \\
Missing due to caries (\%) & $1(2.5)$ & $1(2.4)$ & $0(0.0)$ & $0(0.0)$ & $0(0.0)$ & $0(0.0)$ & $0(0.0)$ & $0(0.0)$ & $3(7.0)$ & $2(4.5)$ \\
Exfoliated (\%) & $0(0.0)$ & $0(0.0)$ & $0(0.0)$ & $0(0.0)$ & $3(37.5)$ & $3(33.4)$ & $1(14.3)$ & $0(0.0)$ & $0(0.0)$ & $0(0.0)$ \\
Total (\%) & $40(100)$ & $43(100)$ & $4(100)$ & $4(100)$ & $8(100)$ & $9(100)$ & $7(100)$ & $7(100)$ & $43(100)$ & $44(100)$ \\
\hline
\end{tabular}

Table 4. Distribution of dental caries (second exam) according to presence of dental caries at first examination, characteristics of child and socioeconomic indicators.

\begin{tabular}{|c|c|c|c|}
\hline \multirow{2}{*}{ Variable } & \multicolumn{2}{|c|}{ New carious lesions } & \multirow{2}{*}{$\mathrm{p}$-value } \\
\hline & Absent n (\%) & Present n (\%) & \\
\hline \multicolumn{4}{|l|}{ Dental caries (first exam) } \\
\hline No & $88(63.3)$ & $51(36.7)$ & - \\
\hline Yes & $37(38.9)$ & $58(61.1)$ & $0.169^{*}$ \\
\hline \multicolumn{4}{|l|}{ Sex } \\
\hline Male & $55(52.4)$ & $50(47.6)$ & - \\
\hline Female & $40(38.1)$ & $50(47.6)$ & $0.438^{* *}$ \\
\hline \multicolumn{4}{|l|}{ Age (years) } \\
\hline 3 & $2(66.7)$ & $1(33.3)$ & - \\
\hline 4 & $40(65.6)$ & $21(34.4)$ & - \\
\hline 5 & $26(40.6)$ & $38(59.4)$ & $0.847^{* * *}$ \\
\hline 6 & $34(51.5)$ & $32(48.5)$ & - \\
\hline 7 & $23(57.5)$ & $17(42.5)$ & - \\
\hline \multicolumn{4}{|l|}{ Oral hygiene } \\
\hline Satisfactory & $74(62.2)$ & $45(37.8)$ & - \\
\hline Unsatisfactory & $51(44.3)$ & $64(55.7)$ & $0.009^{* *}$ \\
\hline \multicolumn{4}{|l|}{ Place of residence } \\
\hline Urban area & $119(54.1)$ & 101 (45.9) & - \\
\hline Rural area & $6(42.9)$ & $8(57.1)$ & $0.582^{* *}$ \\
\hline \multicolumn{4}{|l|}{ Mother's schooling } \\
\hline$>8$ years & $70(56.9)$ & $53(43.1)$ & - \\
\hline$\leq 8$ years & $53(49.1)$ & $55(50.9)$ & $0.238^{* *}$ \\
\hline \multicolumn{4}{|l|}{ Household income ${ }^{c}$} \\
\hline$>2$ times monthly min wage & $103(52.3)$ & $94(47.7)$ & - \\
\hline$\leq 2$ times monthly min wage & $21(58.3)$ & $15(41.7)$ & $0.587^{* *}$ \\
\hline
\end{tabular}

${ }^{*}$ McNemar Test; ${ }^{* *}$ Chi-square test; ${ }^{* * *}$ Chi-square test for linear trend $(p<0.05)$.

lesions were identified by incorporating the variables with a p-value $\leq 0.20$ in the bivariate analysis (caries at first exam and inadequate oral hygiene) into the Poisson regression model with robust variance.
In the adjusted multivariate regression model, only the dental caries at the first examination remained associated with new carious lesions (RR: 1.52; 95\%CI: 1.269-2.182; $\mathrm{p}=0.006$ ) (Table 5). 
Table 5. Relative risk and confidence intervals for associations among caries at first examination, oral hygiene and new carious lesions.

\begin{tabular}{|c|c|c|c|c|c|c|}
\hline Variable & $\begin{array}{l}\text { Relative risk } \\
\text { (unadjusted) }\end{array}$ & $95 \% \mathrm{Cl}$ & $\mathrm{p}$-value & $\begin{array}{c}\text { Relative risk } \\
\text { (adjusted) }\end{array}$ & $95 \% \mathrm{Cl}$ & $p$-value \\
\hline \multicolumn{7}{|c|}{ Dental caries (first exam) } \\
\hline Absent & 1.000 & - & - & 1.000 & - & - \\
\hline Present & 1.664 & $1.26-2.18$ & $<0.001$ & 1.525 & $1.12-2.05$ & 0.006 \\
\hline \multicolumn{7}{|l|}{ Oral hygiene } \\
\hline Satisfactory & 1.000 & - & - & 1.000 & - & - \\
\hline Unsatisfactory & 1.472 & $1.10-1.95$ & 0.007 & 1.238 & $0.91-1.68$ & 0.172 \\
\hline
\end{tabular}

\section{Discussion}

In the present study, approximately $46 \%$ of the children had new carious lesions over a period of two years. The incidence was even greater among children who had caries at the first examination (61.1\%). The high incidence of dental caries in the primary dentition is in agreement with studies conducted on children in Thailand ${ }^{18}$ and Sweden. ${ }^{19}$

Children with dental caries at the first examination were 1.52 times more likely to experience new dental caries over the two-year period. Thus, previous dental caries was a predictor for new dental caries. This finding lends support to the hypothesis that previous caries experience is indicative of the disease in the future, ${ }^{16,24,25,26}$ especially in cases in which children are exposed to other risk factors for dental caries.

Inadequate oral hygiene (assessed in the present study by the presence of biofilm that adhered to the tooth surface) was associated with new carious lesions in the bivariate analysis. Biofilm is related to the presence of cariogenic bacteria and fermentable substances, which leads to demineralization and dental caries. ${ }^{6}$ Brushing with fluoridated toothpaste is one of the measures for caries prevention. ${ }^{27}$ However, this preventive measure may be inadequate in young children, due to their poor dexterity. ${ }^{28}$ Thus, brushing should be practiced or supervised by parents/caregivers until the child is able to perform it alone. ${ }^{6}$ Indeed, the association between dental caries and the recurrence of visible plaque may be related to a lack of oral hygiene monitoring by parents/caregivers. However, the multivariate model revealed that oral hygiene did not remain associated with new carious lesions. This finding may be explained by the collinearity between oral hygiene and caries at the first exam. Thus, although this variable did not remain significant, it must be considered when investigating the risk of tooth decay.

Although the parents/caregivers were counseled regarding the importance of controlling factors associated with tooth decay, as well as the measures to be adopted for the prevention and control of the disease, the incidence of dental caries was high. This finding seems to be associated with the difficulty of understanding such measures on the part of parents/caregivers, or else the low priority given to oral health care. ${ }^{29}$ In this respect, one must consider the influence of environmental and socioeconomic factors. While families may agree to follow the recommendations of dental professionals for the maintenance of their children's oral health, aspects such as level of comprehension and poor living conditions, as well as limited availability and access to health services may compromise the adoption and success of preventive measures. The present findings lend support to this hypothesis, insofar as new caries occurred more in children from families with a low socioeconomic status, although no statistically significant association was found between socioeconomic indicators and dental caries incidence. The absence of an association may be related to the fact that the sample is homogeneous with respect to socioeconomic indicators (place of residence, mother's schooling and household income). This makes it difficult to identify differences in the incidence of dental caries among children with higher or lower socioeconomic status.

Only $27.4 \%$ of children with dental caries diagnosed at the first examination had at least one treated tooth. The lack of treatment seems to reflect the lives of these children, and confirms that socioeconomic inequalities and limited access to health services exert an influence on the oral health of preschool children. ${ }^{12,13,28}$ 
This study has limitations due to the rate of sample loss caused by the high degree of mobility of the families. However, it also has strengths, such as the longitudinal design, which allowed the assessment of caries incidence and the establishment of a causal relationship among the variables. Moreover, this investigation provides greater evidence to complement earlier research, since the sample was taken from a population-based study.

The present findings demonstrate that dental caries still affects a large number of children and is a risk factor for developing further caries. Although this disease is a common occurrence in the primary dentition, its treatment is neglected; this can affect the quality of life of children and their families. ${ }^{30}$ Thus, given the growing number of carious lesions in the primary dentition and the high proportion of children without dental treatment, this study underscores

\section{References}

1. Baelum V, van Palenstein Helderman WH, Hugoson A, Yee R, Fejerskov O. A global perspective on changes in the burden of caries and periodontitis: implications for dentistry. J Oral Rehabil. 2007;34(12):872-906. doi:10.1111/j.1365-2842.2007.01799.x

2. Abanto J, Tsakos G, Paiva SM, Carvalho TS, Raggio DP, Bönecker M. Impact of dental caries and trauma on quality of life among 5- to 6-year-old children: perceptions of parents and children. Community Dent Oral Epidemiol. 2014;42(5):385-94. doi:10.1111/cdoe.12099

3. Corrêa-Faria P, Martins-Júnior PA, Vieira-Andrade RG, Marques LS, Ramos-Jorge ML. Factors associated with the development of early childhood caries among Brazilian preschoolers. Braz Oral Res. 2013;27(4):356-62. doi:10.1590/S1806-83242013005000021

4. Leong PM, Gussy MG, Barrow S-Y, Silva-Sanigorski A, Waters E. A systematic review of risk factors during first year of life for early childhood caries. Int J Paediatr Dent. 2013;23(4):235-50. doi:10.1111/j.1365-263X.2012.01260.x

5. Azevedo MS, Romano AR, Santos IS, Cenci MS. Knowledge and beliefs concerning early childhood caries from mothers of children ages zero to 12 months. Pediatr Dent. 2014;36(3):95E-99E.

6. Castilho AR, Mialhe FL, Barbosa TS, Puppin-Rontani RM. Influence of family environment on children's oral health: a systematic review. J Pediatr (Rio J). 2013;89(2):116-23. doi:10.1016/j.jped.2013.03.014 the need to establish public policies and prevention programs aimed at reducing the incidence of dental caries and increasing access to oral health services.

\section{Conclusions}

The incidence of caries in the primary dentition was high and the majority of children received no dental treatment. A previous caries experience in the primary dentition is a risk factor for developing new carious lesions in children.

\section{Acknowledgments}

This study had the support of the following Brazilian agencies: Conselho Nacional de Desenvolvimento Científico e Tecnológico - CNPq, Ministério da Ciência, Tecnologia e Inovação - MCT and Fundação de Amparo à Pesquisa do Estado de Minas Gerais - FAPEMIG.

7. Corrêa-Faria P, Paixão-Gonçalves S, Paiva SM, Pordeus IA, Marques LS, Ramos-Jorge ML. Association between developmental defects of enamel and early childhood caries: a cross-sectional study. Int J Paediatr Dent. 2015;25(2):103-9. doi:10.1111/ipd.12105

8. Scarpelli AC, Paiva SM, Viegas CM, Carvalho AC, Ferreira FM, Pordeus IA. Oral health-related quality of life among Brazilian preschool children. Community Dent Oral Epidemiol. 2013;41(4):336-44. doi:10.1111/cdoe.12022

9. Oliveira LB, Sheiham A, Bönecker M. Exploring the association of dental caries with social factors and nutritional status in Brazilian preschool children. Eur J Oral Sci. 2008;116(1):37-43. doi:10.1111/j.1600-0722.2007.00507.x

10. Lee GH, McGrath C, Yiu CK, King NM. A comparison of a generic and oral health-specific measure in assessing the impact of early childhood caries on quality of life. Community Dent Oral Epidemiol. 2010;38(4):333-9. doi:10.1111/j.1600-0528.2010.00543.x

11. Moimaz SAS, Fadel CB, Lolli LF, Garbin CA, Garbin AJ, Saliba NA. Social aspects of dental caries in the context of mother-child pairs. J Appl Oral Sci. 2014;22(1):73-8. doi:10.1590/1678-775720130122

12. Narang R, Saha S, Jagannath GV, Kumari M, Mohd S, Saha $S$. The maternal socioeconomic status and the caries experience among 2-6 years old preschool children of lucknow city, India. J Clin Diagn Res. 2013;7(7):1511-3. doi:10.7860/JCDR/2013/5213.3176 
13. Ardenghi TM, Piovesan C, Antunes JLF. Inequalities in untreated dental caries prevalence in preschool children in Brazil. Rev Saude Publica. 2013;47 Suppl 3:129-37. doi:10.1590/S0034-8910.2013047004352

14. Sheiham A. Dental caries affects body weight, growth and quality of life in pre-school children. Br Dent J. 2006;201(10):625-6. doi:10.1038/sj.bdj.4814259

15. Alsharif AT, Kruger E, Tennant M. Dental hospitalization trends in Western Australian children under the age of 15 years: a decade of population-based study. Int J Paediatr Dent. 2015;25(1):35-42. doi:10.1111/ipd.12095

16. Tagliaferro EP, Pereira AC, Meneghim MC, Ambrosano GM. Assessment of dental caries predictors in a seven-year longitudinal study. J Public Health Dent. 2006;66(3):169-73. doi:10.1111/j.1752-7325.2006.tb02575.x

17. Burt BA. Definitions of risk. J Dent Educ 2001;65(10):1007-8.

18. Peltzer K, Mongkolchati A, Satchaiyan G, Rajchagool S, Pimpak T. Sociobehavioral factors associated with caries increment: a longitudinal study from 24 to 36 months old children in Thailand. Int J Environ Res Public Health. 2014;11(10):10838-50. doi:10.3390/ijerph111010838

19. André Kramer AC, Skeie MS, Skaare AB, Espelid I, Ostberg A-L. Caries increment in primary teeth from 3 to 6 years of age: a longitudinal study in Swedish children. Eur Arch Paediatr Dent. 2014;15(3):167-73. doi:10.1007/s40368-013-0079-7

20. Programa das Nações Unidas para o Desenvolvimento. Atlas de Desenvolvimento Humano no Brasil [Internet]. Brasília (DF): ONU; 2003 [cited 2013 Dec 5]. Available from: http://www.pnud.org.br/atlas/ranking/IDH_Municipios_ Brasil_2000.aspx?indiceAccordion = 1\&li=li_Ranking2003

21. Instituto Brasileiro de Geografia e Estatística [Internet]. Brasília (DF): IBGE; 2010 [cited 2013 Dec 5]. Available from: http://www.ibge.gov.br/cidadesat/topwindow.htm?1

22. Nogueira LC, Resende NFB, Ferraz NKL, Corrêa-Faria P, Marques LS, Ramos-Jorge ML. Prevalence of dental caries in children aged 6 to 60 months and associated factors in Diamantina, Minas Gerais, Brazil. Pesqui Bras Odontopediatri Clin Integr. 2012;12(1):13-7. doi:10.4034/PBOCI.2012.121.02

23. World Health Organization. Oral Health Surveys: basic methods [Internet]. 4th ed. Geneva: World Health Organization; 1997 [cited 2013 Dec 5]. Available from: http://www2.paho.org/hq/dmdocuments/2009/OH_ st_Esurv.pdf

24. van Palenstein Helderman WH, Mulder J, van'T Hof MA, Truin GJ. Validation of a Swiss method of caries prediction in Dutch children. Community Dent Oral Epidemiol. 2001;29(5):341-5. doi:10.1034/j.1600-0528.2001.290503.x

25. Farsi N, Merdad L, Mirdad S. Caries risk assessment in preschool children in Saudi Arabia. Oral Health Prev Dent. 2013;11(3):271-80. doi:10.3290/j.ohpd.a30479

26. Guedes RS, Piovesan C, Ardenghi TM, Emmanuelli B, Braga MM, Ekstrand KR, et al. Validation of visual caries activity assessment: a 2-yr cohort study. J Dent Res. 2014;93(7 Suppl):101S-107S. doi:10.1177/0022034514531017

27. Al-Mendalawi MD, Karam NT. Risk factors associated with deciduous tooth decay in Iraqi preschool children. Avicenna J Med. 2014;4(1):5-8. doi:10.4103/2231-0770.127414

28. Subramaniam P, Prashanth P. Prevalence of early childhood caries in 8 - 48 month old preschool children of Bangalore city, South India. Contemp Clin Dent. 2012;3(1):15-21. doi:10.4103/0976-237X.94540

29. Divaris K, Lee JY, Baker AD, Gizlice Z, Rozier RG, DeWalt DA, et al. Influence of caregivers and children's entry into the dental care system. Pediatrics 2014;133(5):e1268-76. doi:10.1542/peds.2013-2932

30. Ramos-Jorge J, Pordeus IA, Ramos-Jorge ML, Marques LS, Paiva SM. Impact of untreated dental caries on quality of life of preschool children: different stages and activity. Community Dent Oral Epidemiol. 2014;42(4):311-22. doi:10.1111/cdoe.12086 